\title{
Direct Oxidative Amidation of Aldehydes with Anilines under Mechanical Milling Conditions
}

\author{
Jie Gao and Guan-Wu Wang* \\ Hefei National Laboratory for Physical Sciences at Microscale, Joint Laboratory of \\ Green Synthetic Chemistry, and Department of Chemistry, University of Science and \\ Technology of China, Hefei, Anhui 230026, P. R. China. \\ Fax \& Tel: +86-551-360-7864; E-mail: gwang@ustc.edu.cn
}

\section{List of Contents}

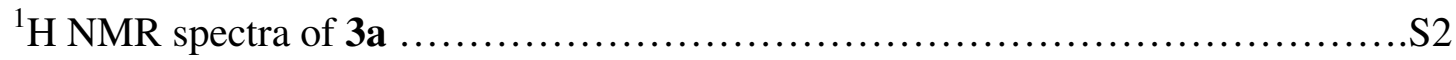

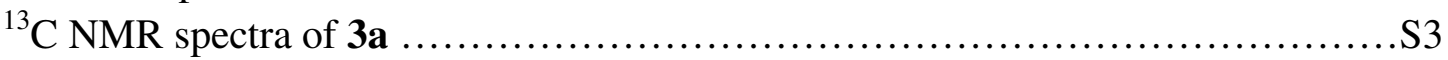

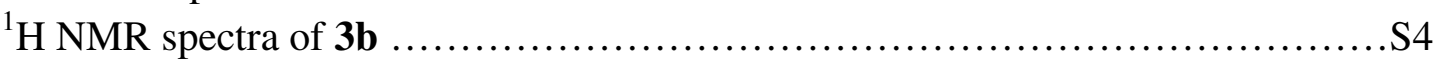

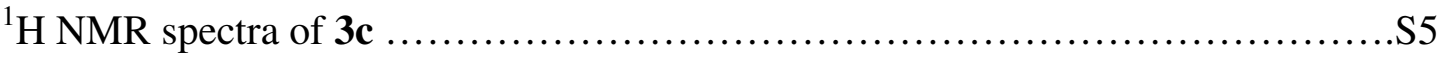

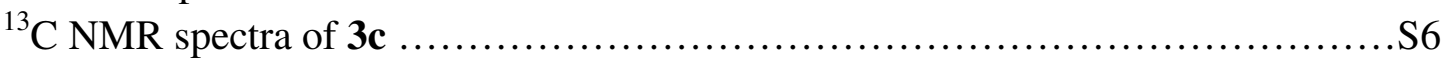

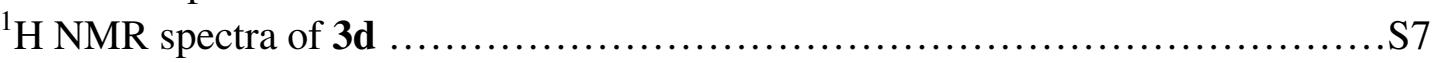

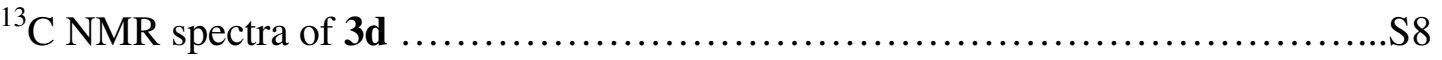

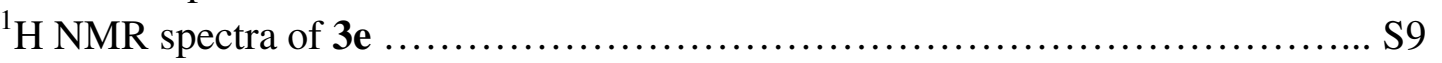

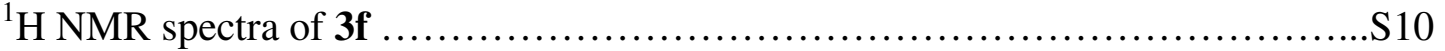

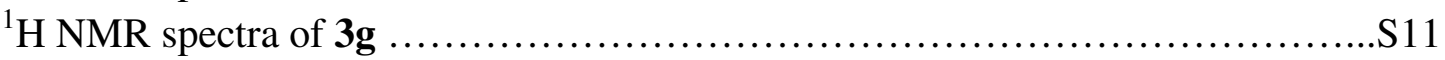

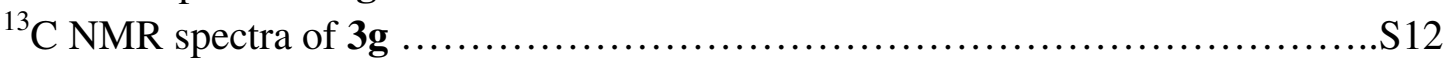

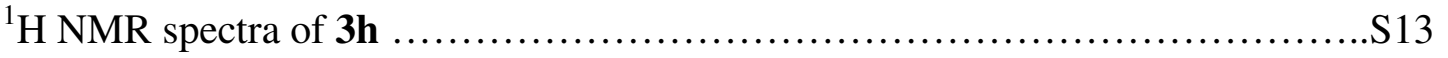

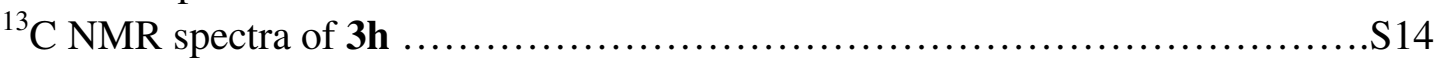

${ }^{1} \mathrm{H}$ NMR spectra of $\mathbf{3 i}$.................................................... 15

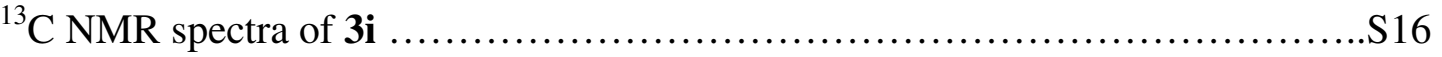

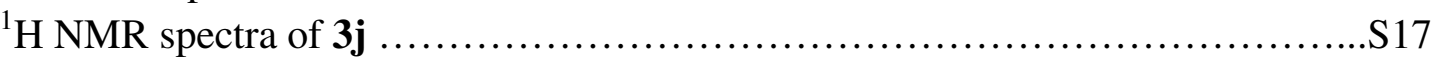

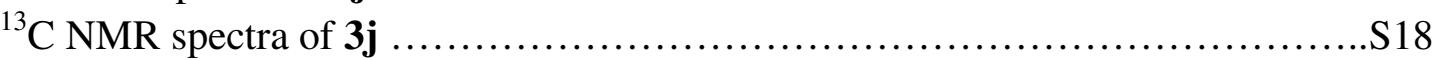

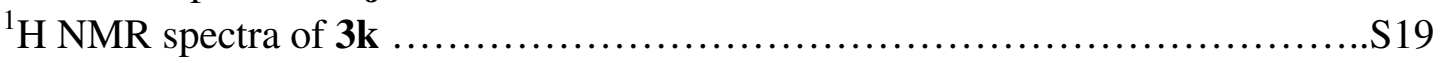




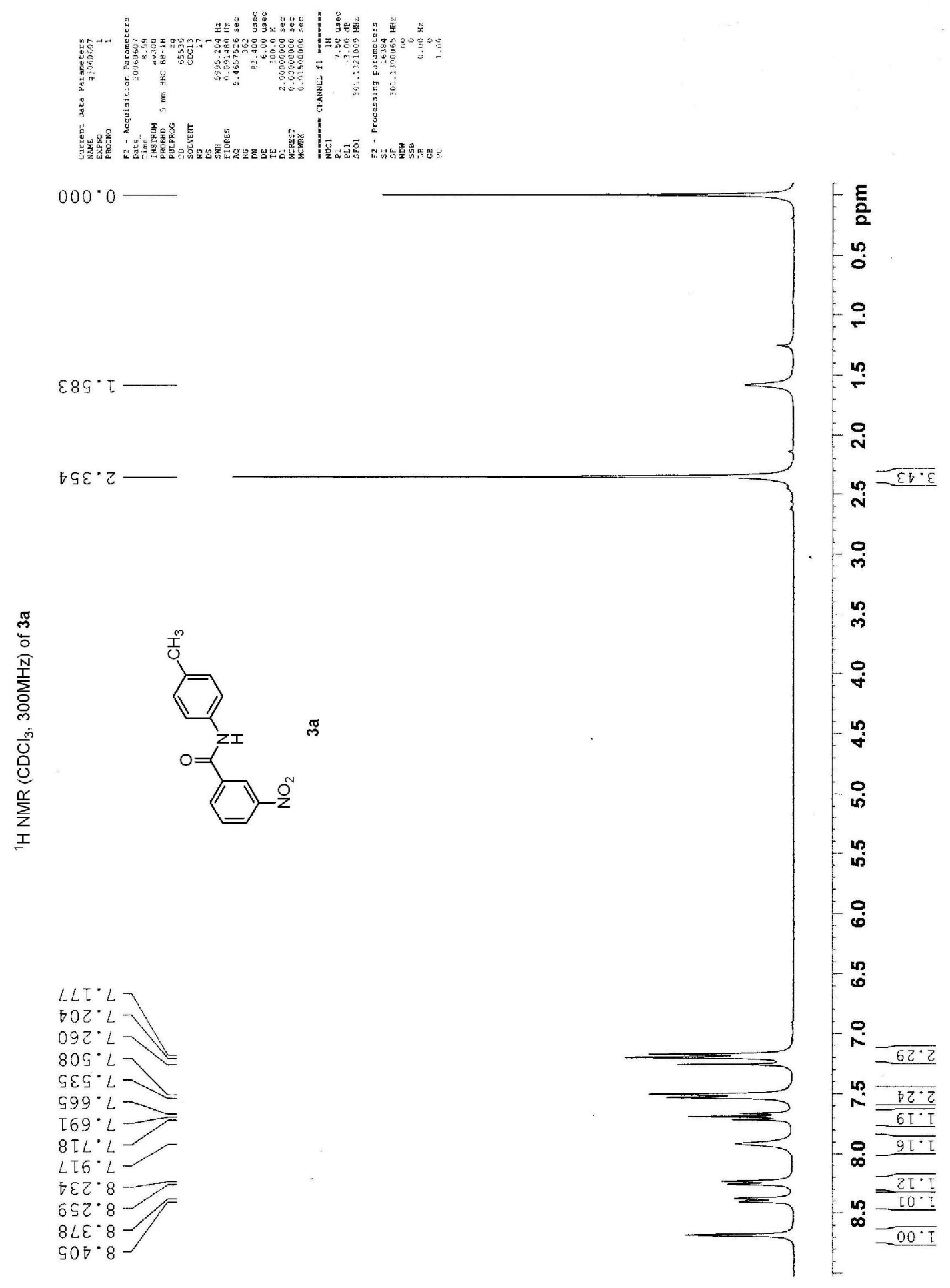



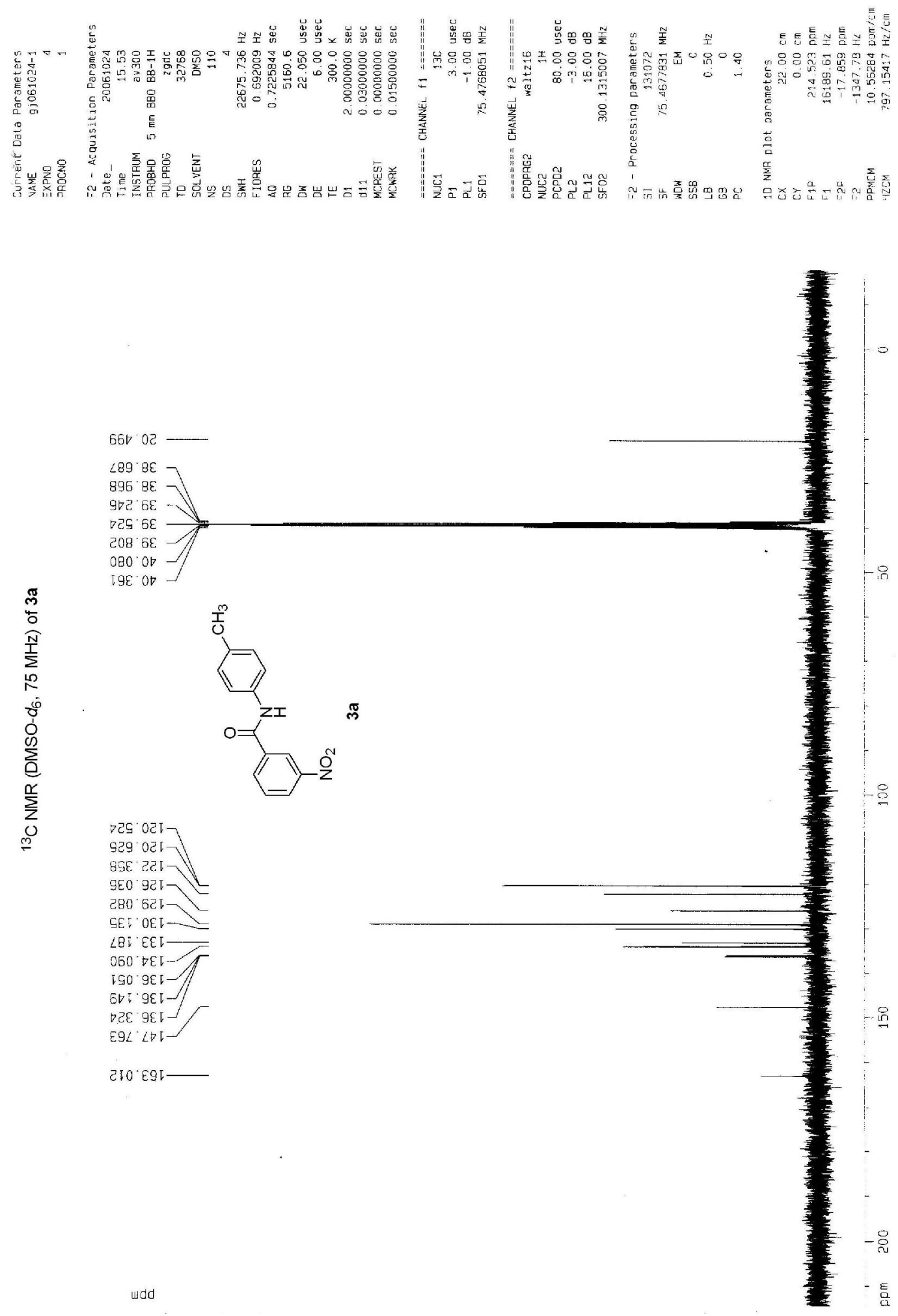


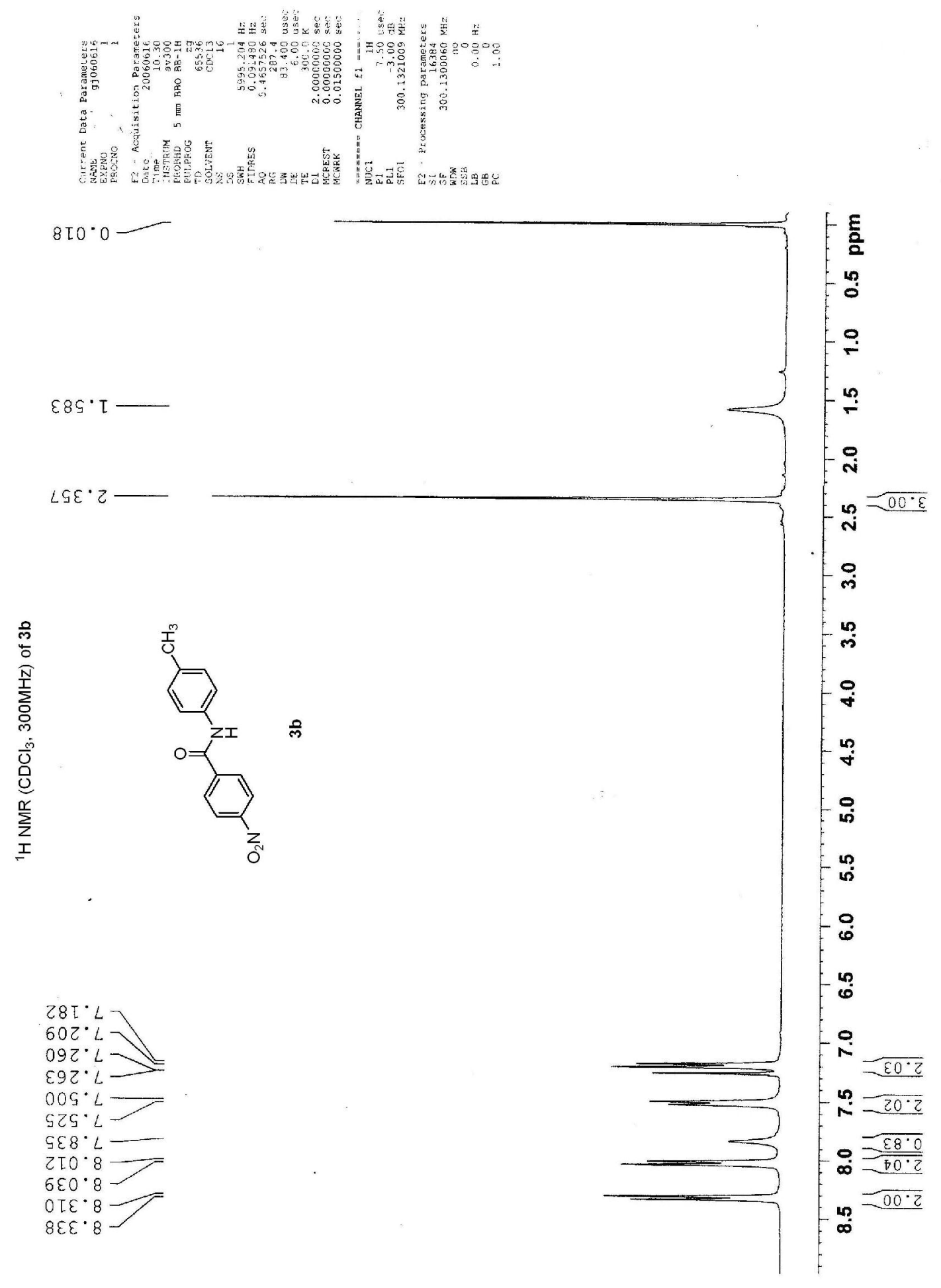



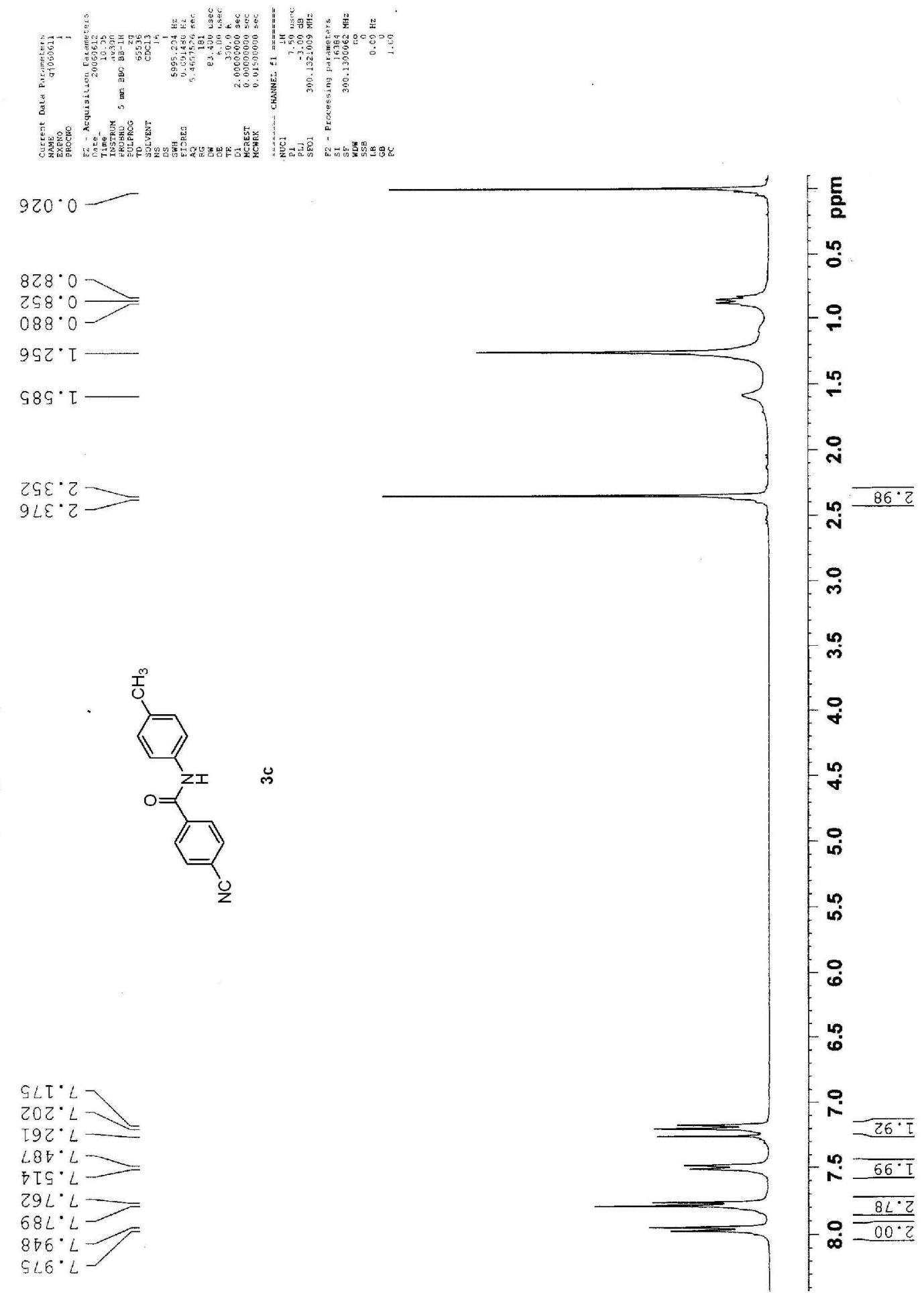

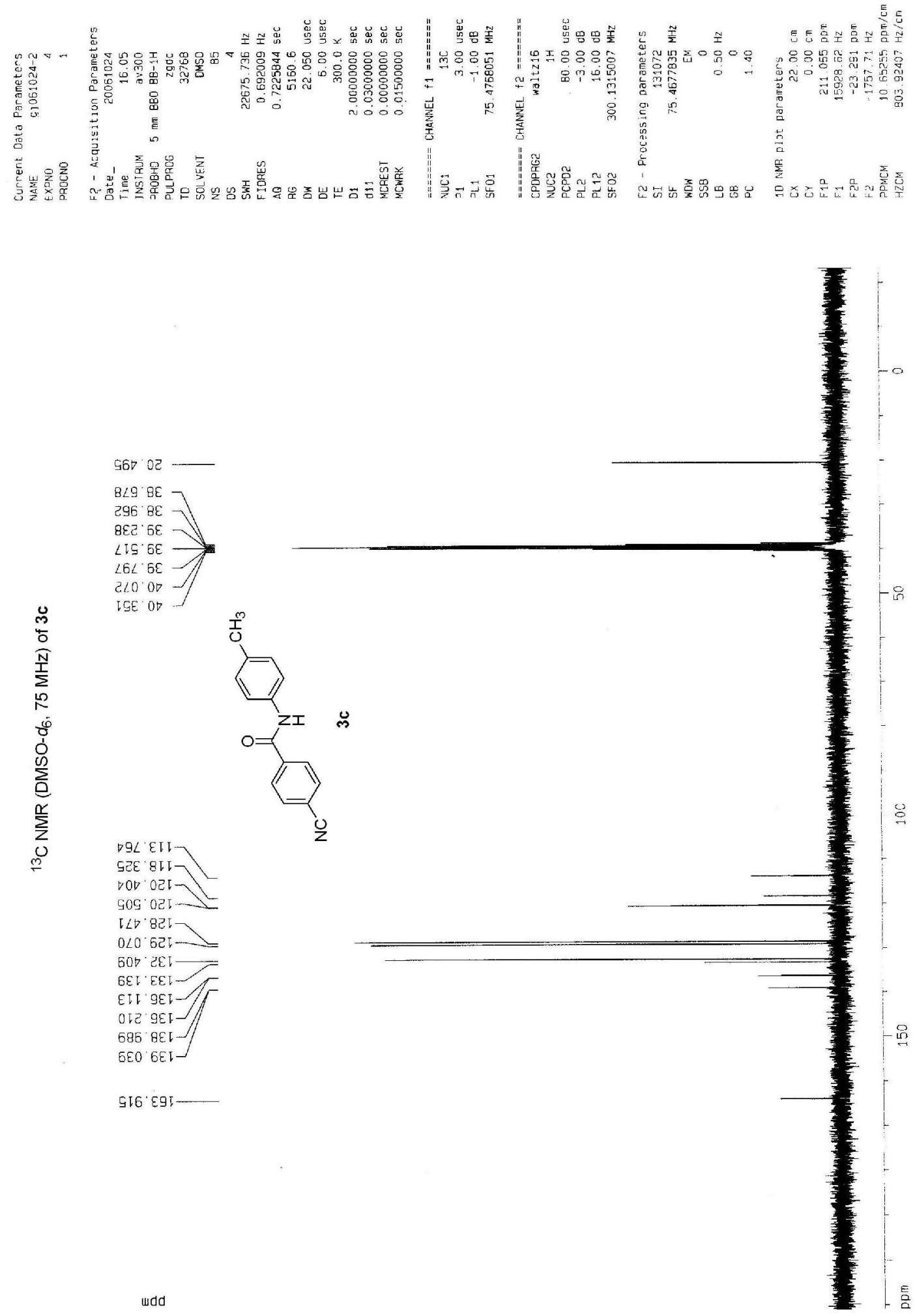


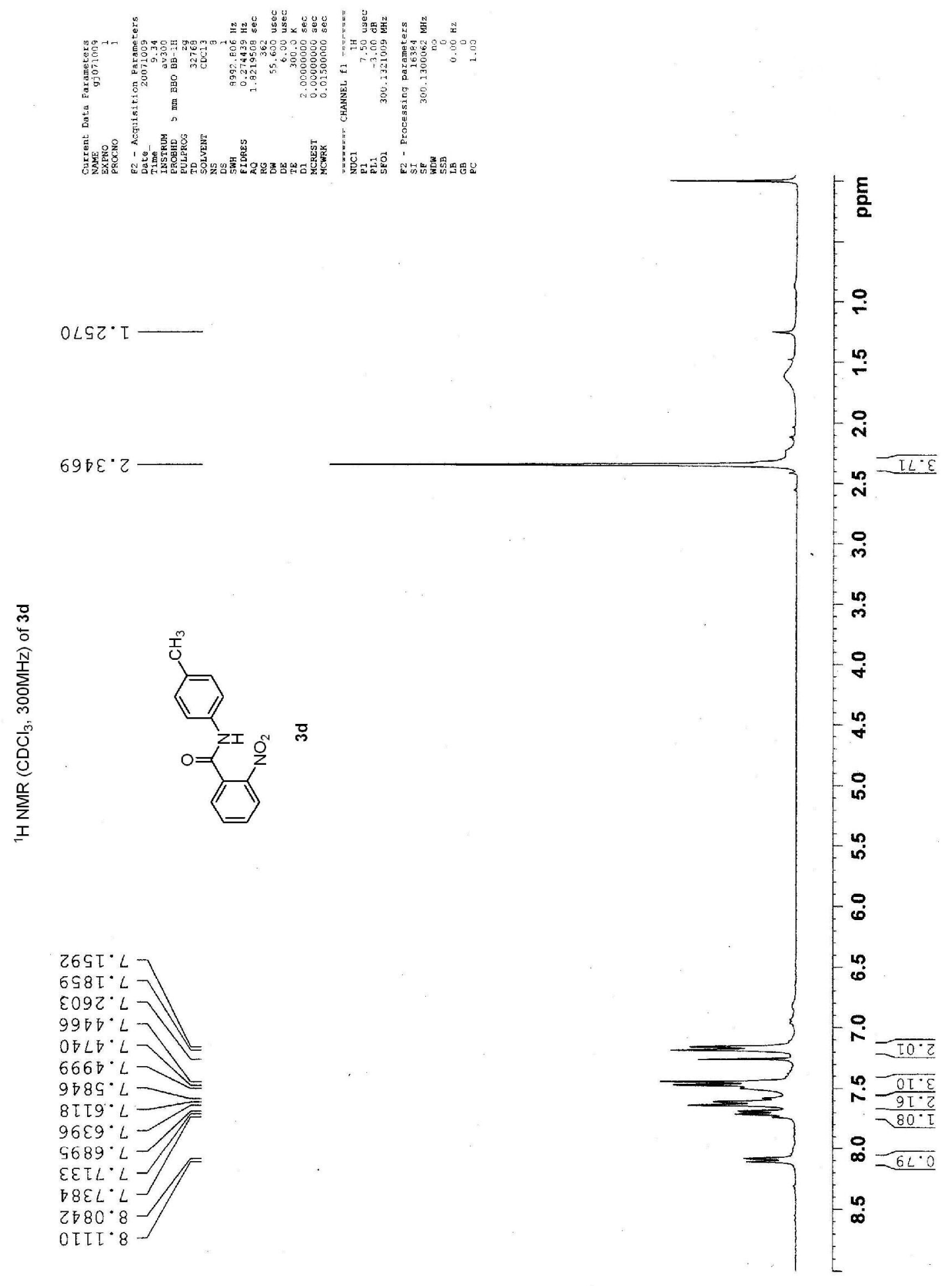



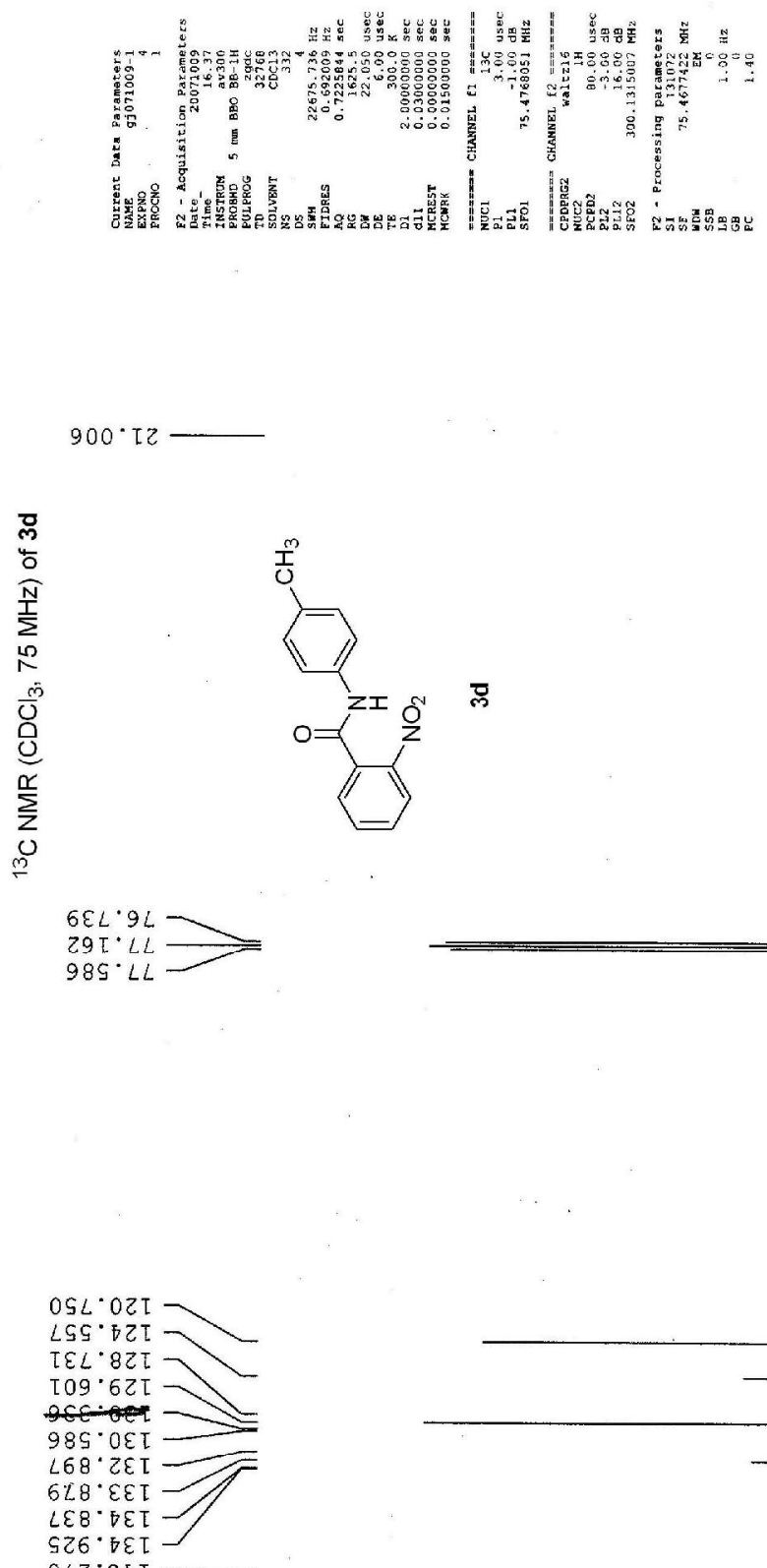

$989 \cdot 69 \tau$

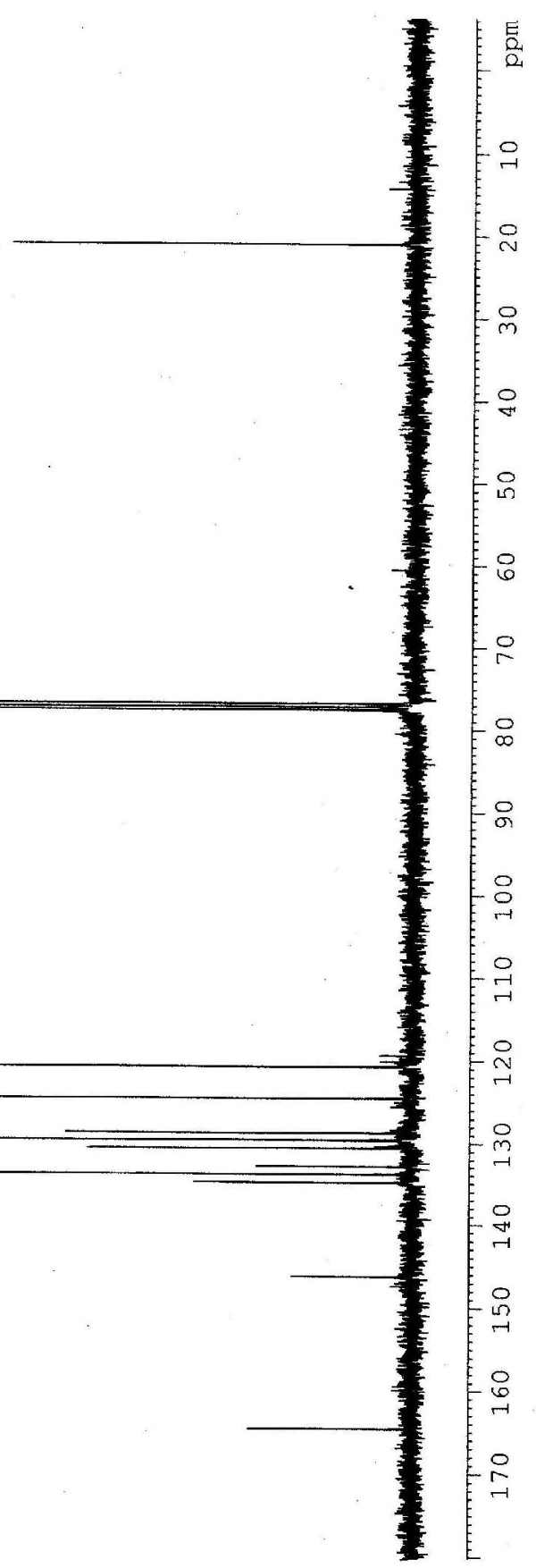




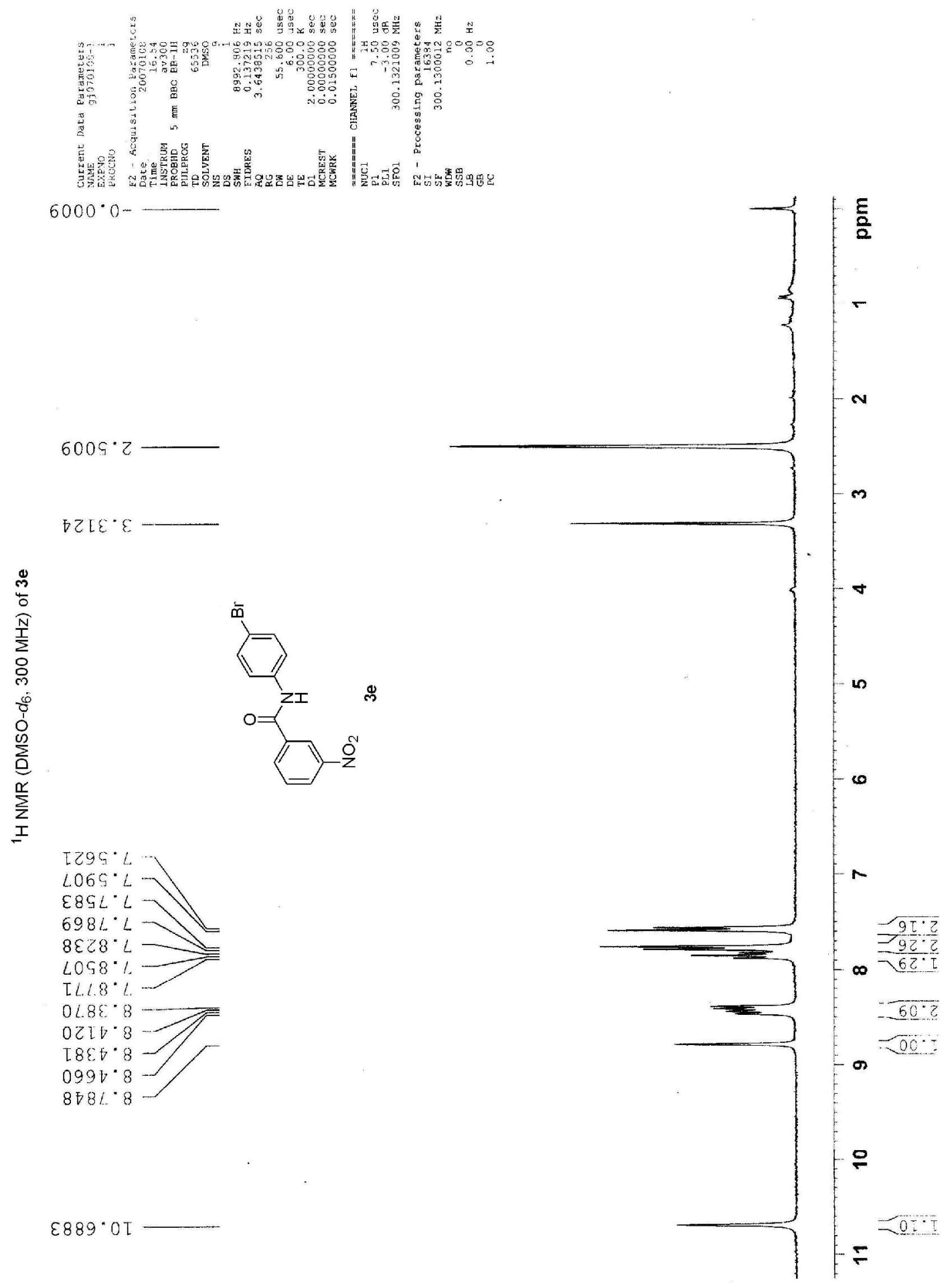



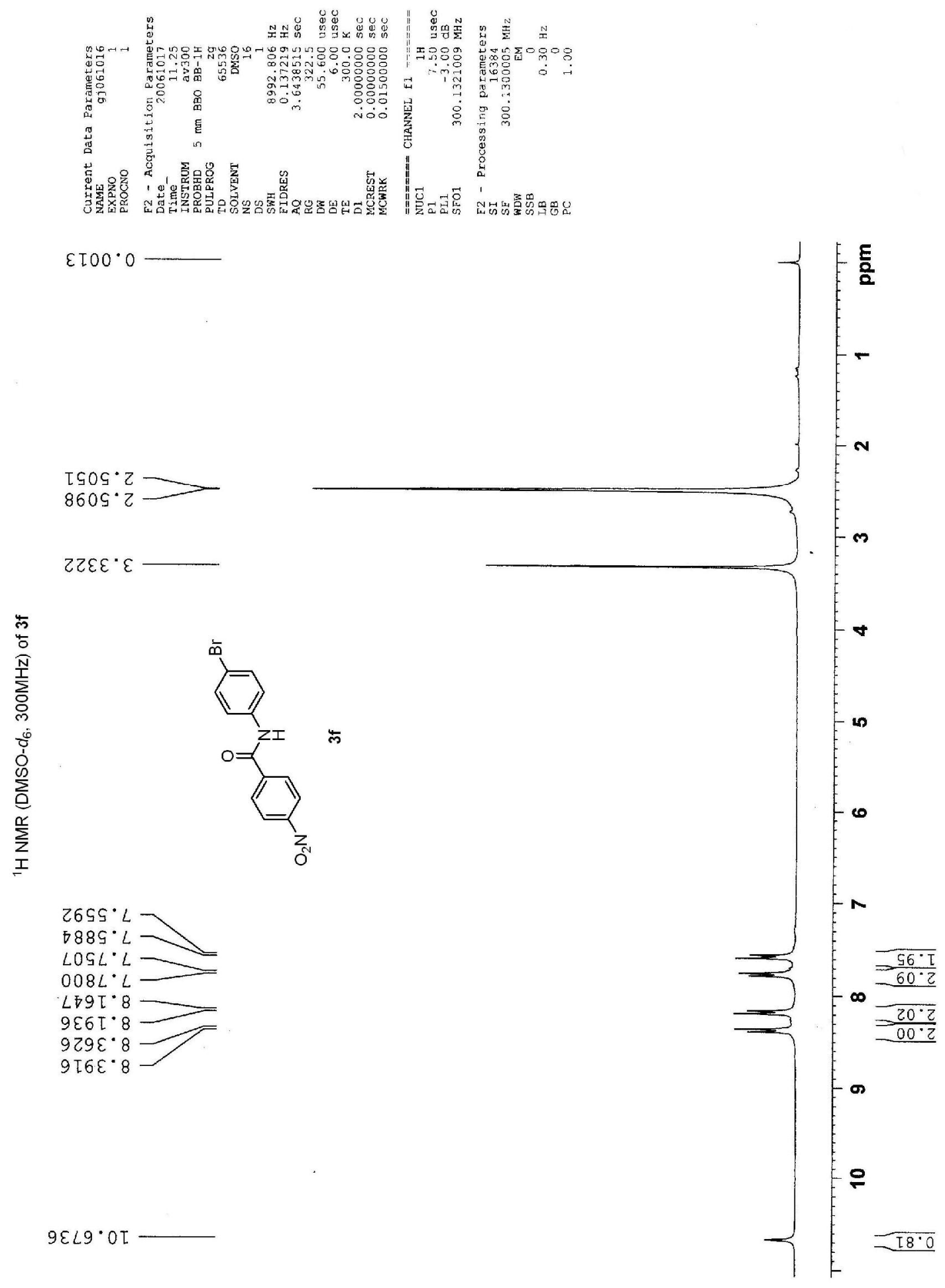

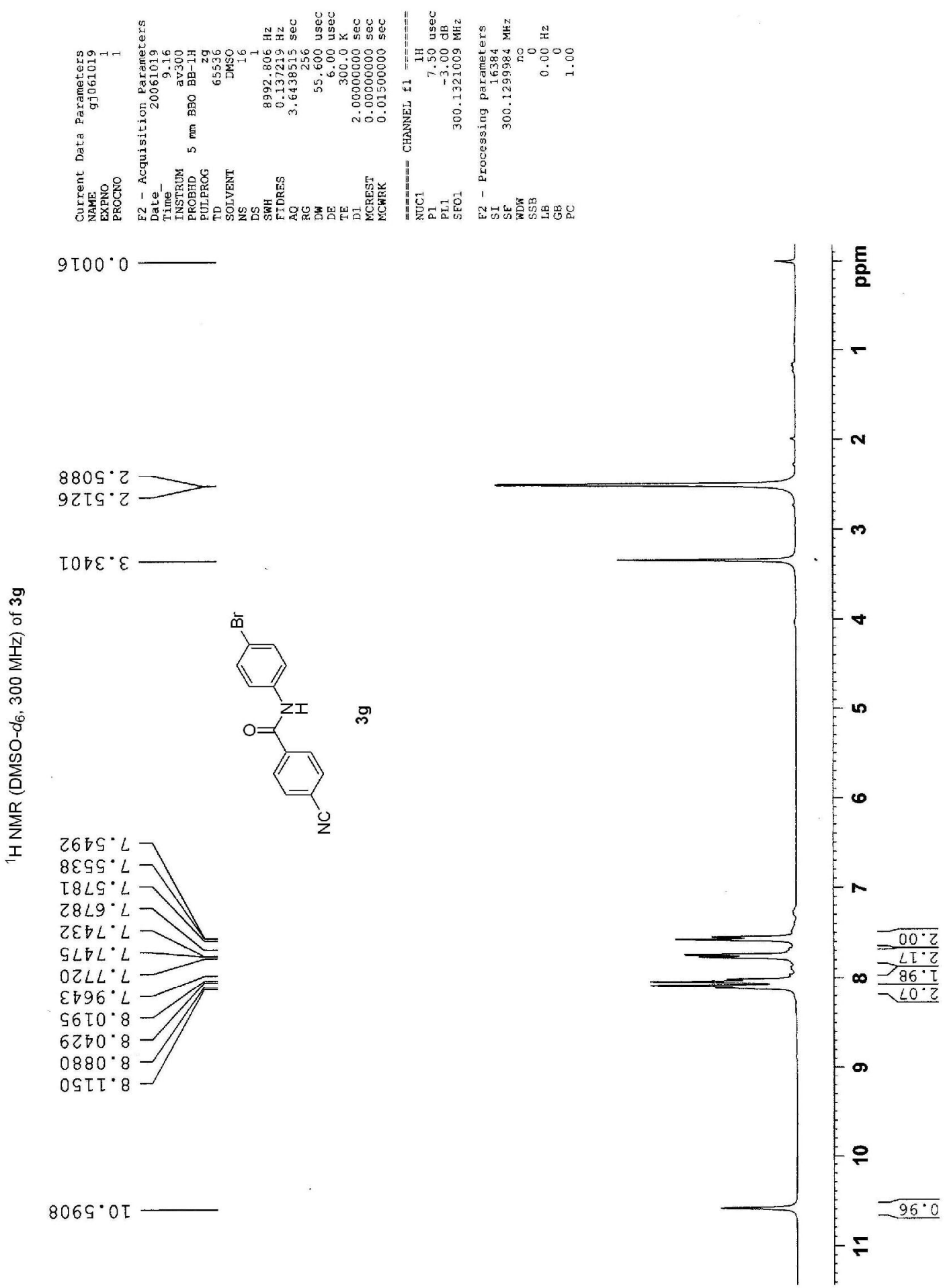

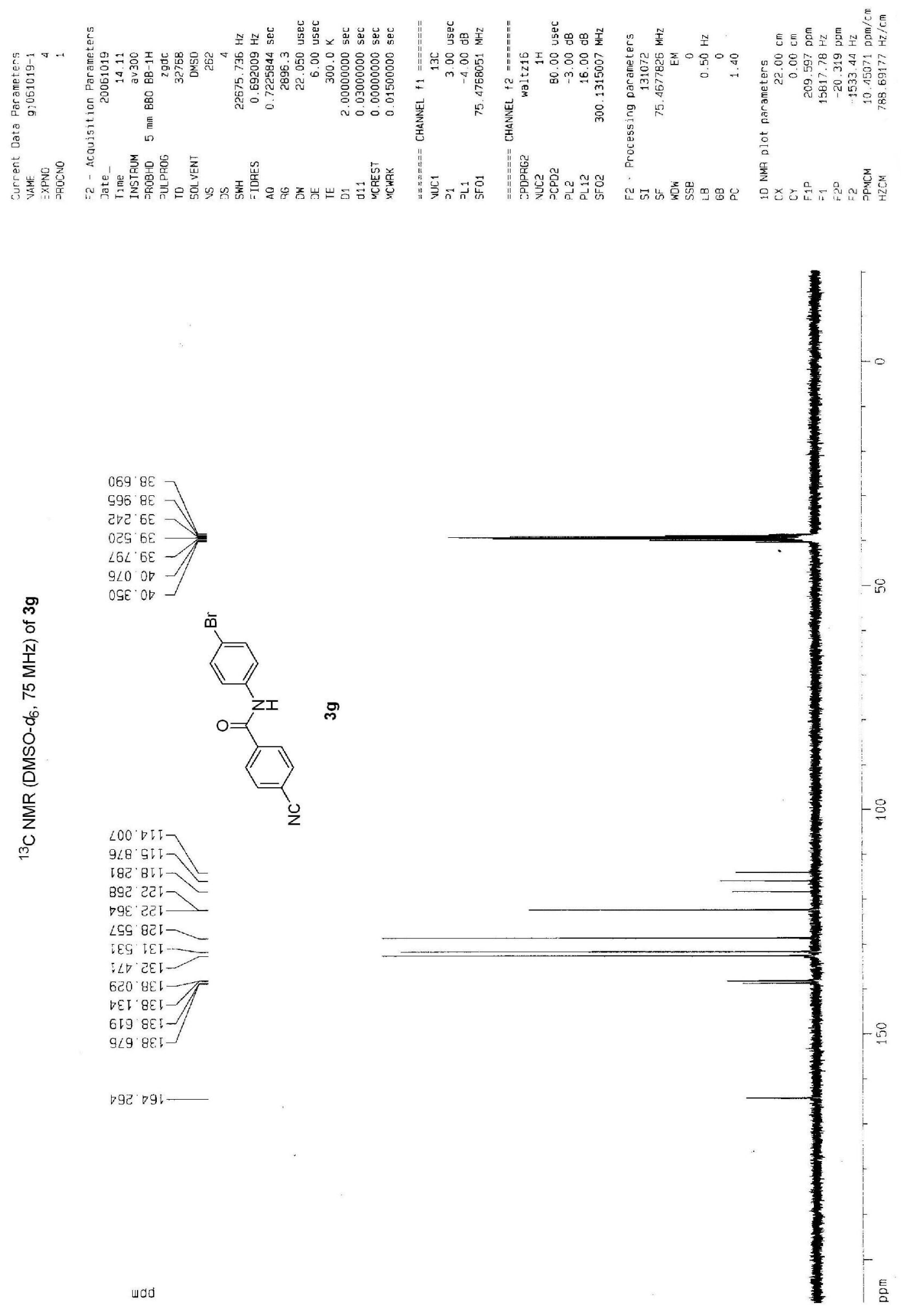

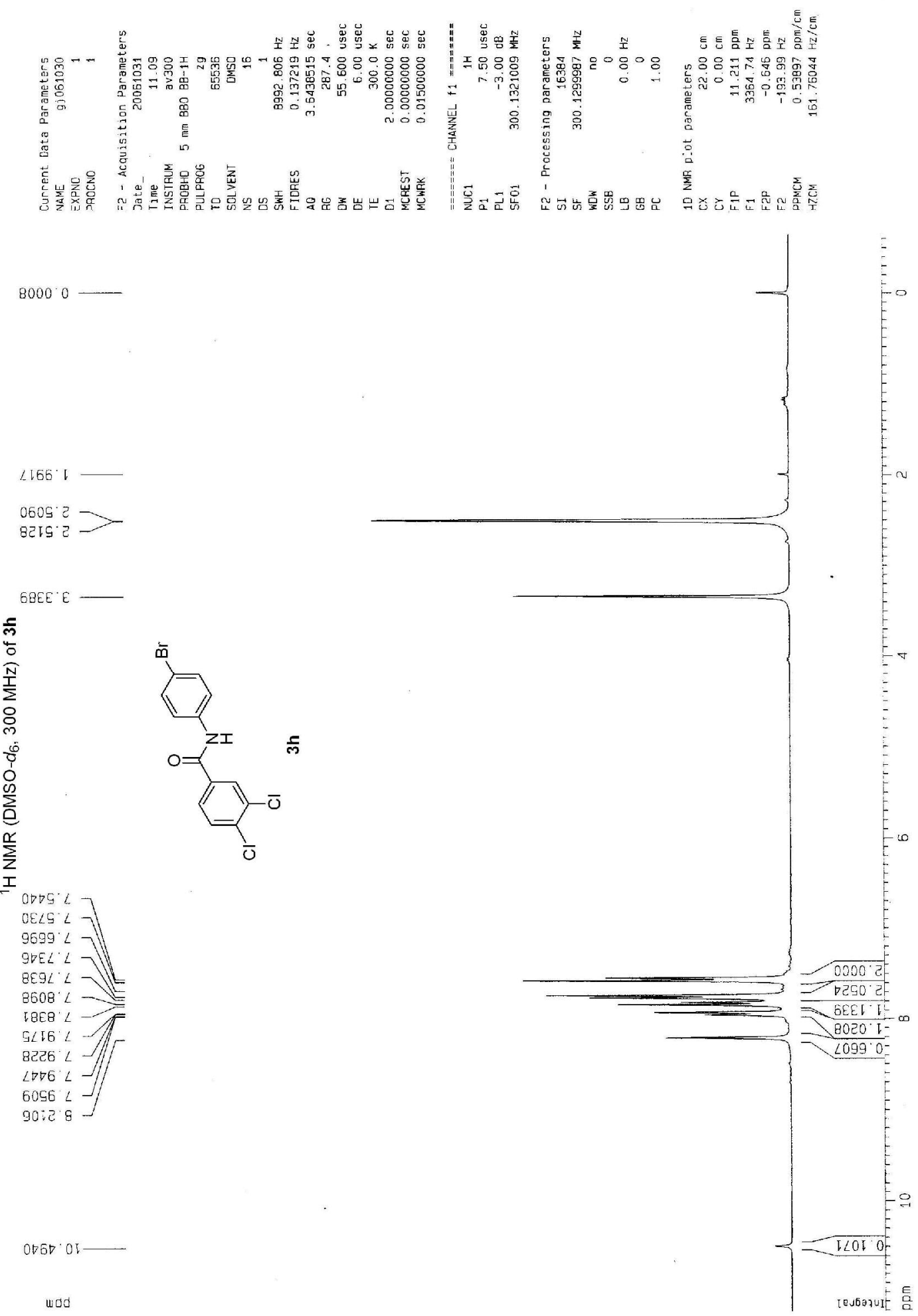


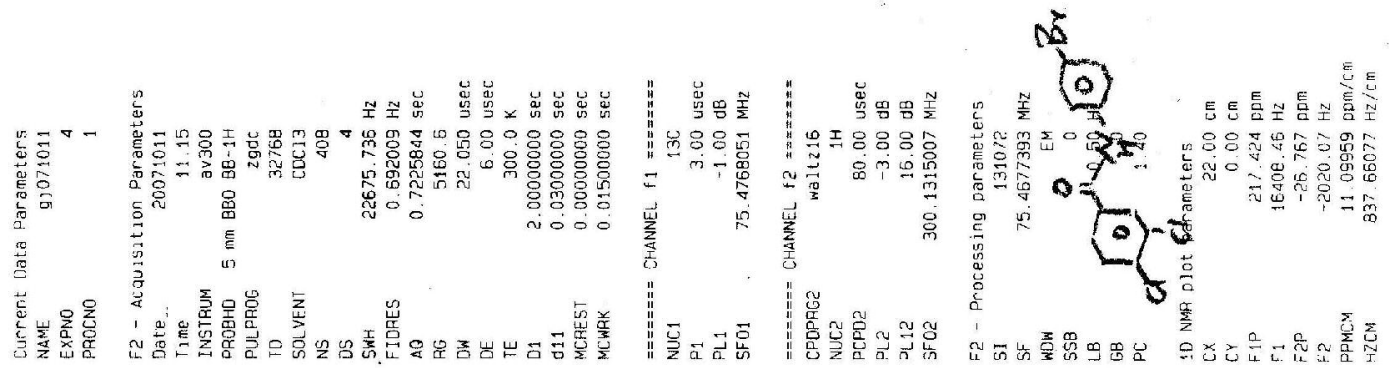

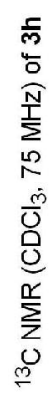

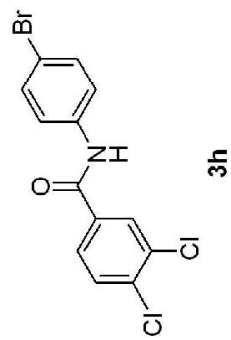

sel $9 L>$
$091 \angle L>$
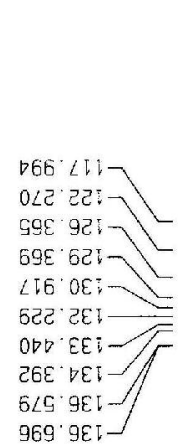

Eจ6 $\varepsilon 9 \downarrow$

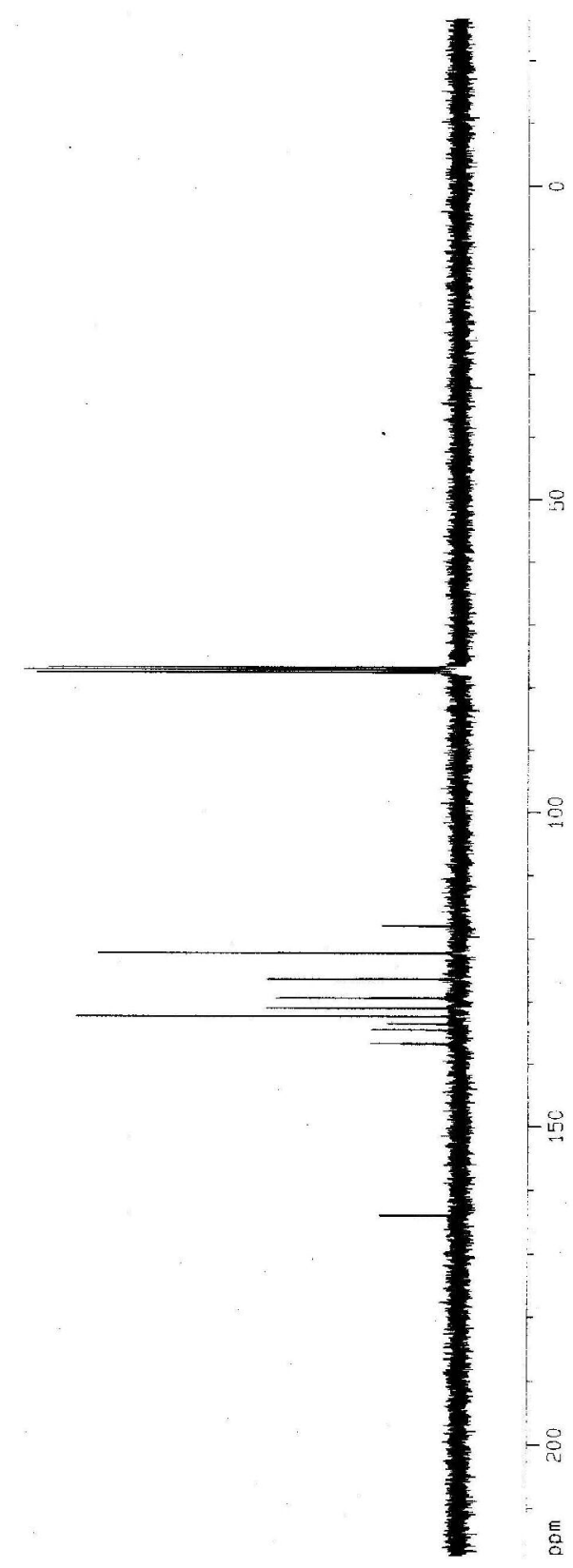




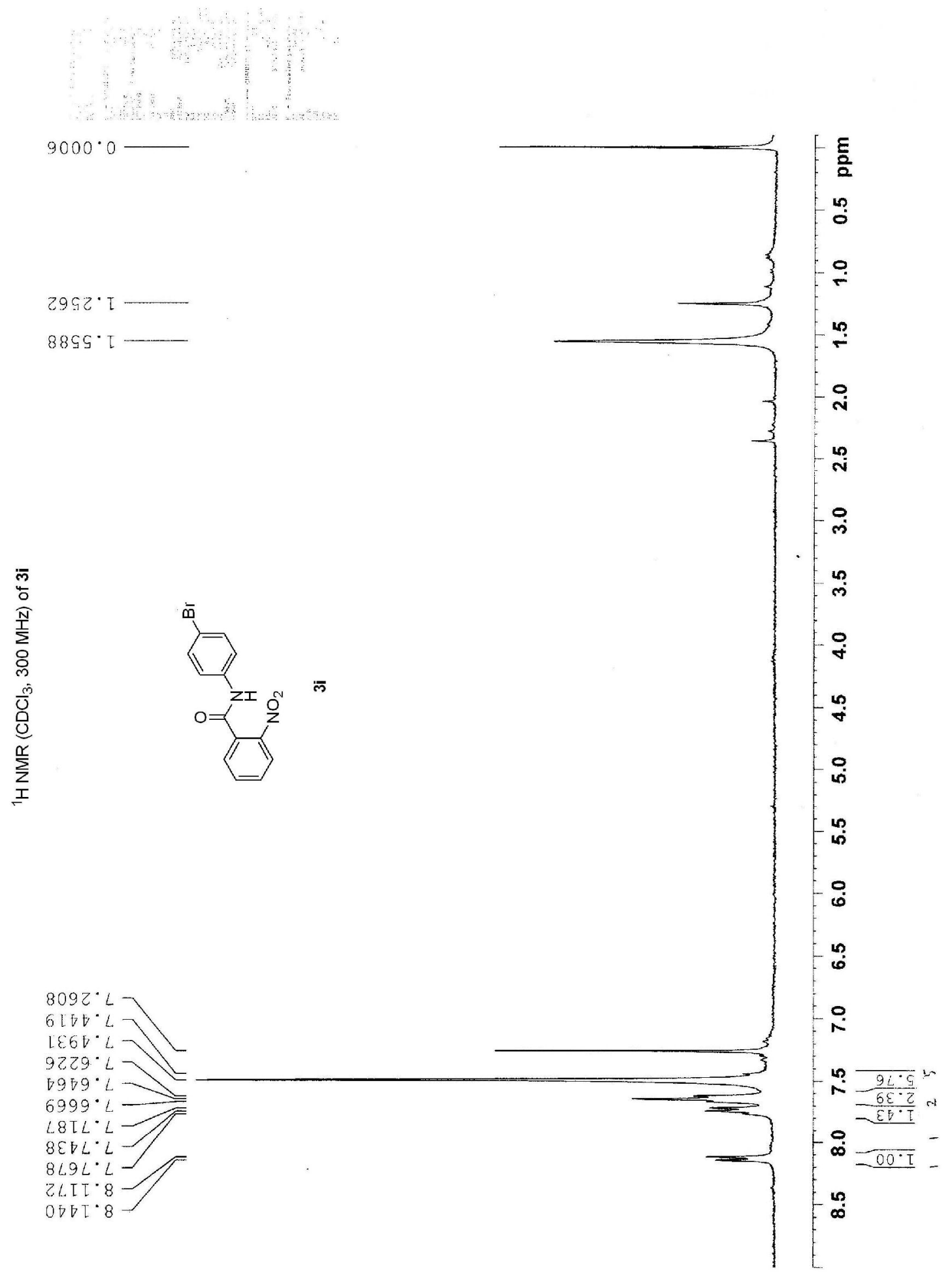




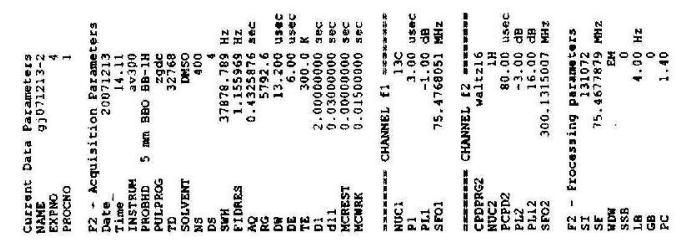

\author{
列
}

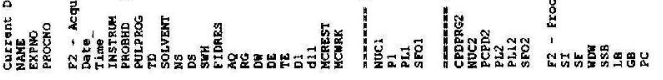

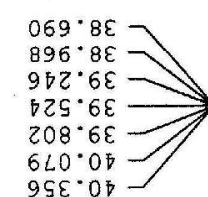

9SE. OD

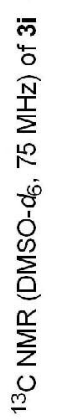

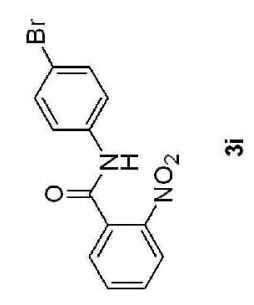

ZTو. ST

$6 \circ G^{\circ} T Z L$

$\angle D Z \cdot B Z I$

$\angle 26 \cdot 821>$

$\varepsilon 22 \cdot 62 \mathrm{I}$

ธEО TहL

โEg 'TE I

$00 \nabla^{\circ} 2 \varepsilon \mathrm{L}$

$\mathrm{T} 60^{\circ} \mathrm{DCT}$

$6 \mathrm{ST} \cdot 8 \varepsilon \mathrm{T}$

$\varepsilon 9 \varepsilon^{\circ} 9 \hbar \tau$

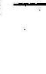

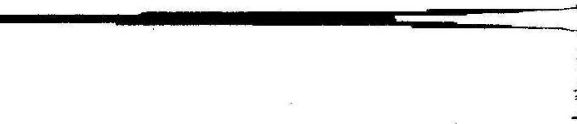

年落

ㅇ

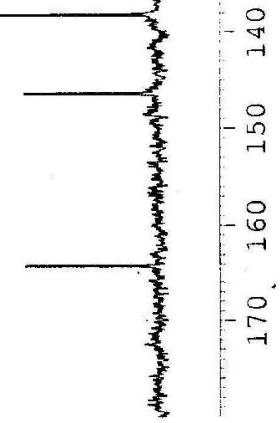




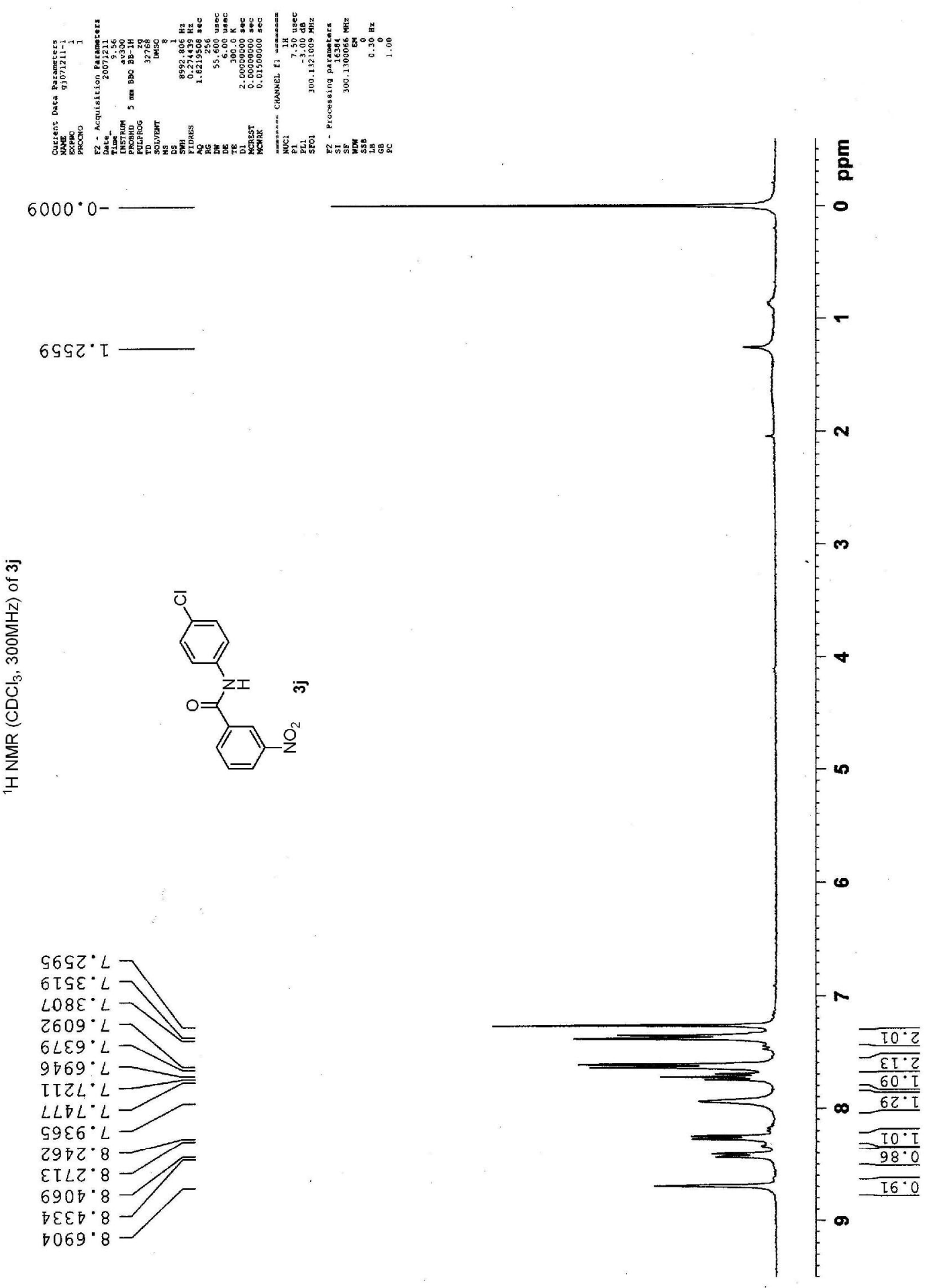




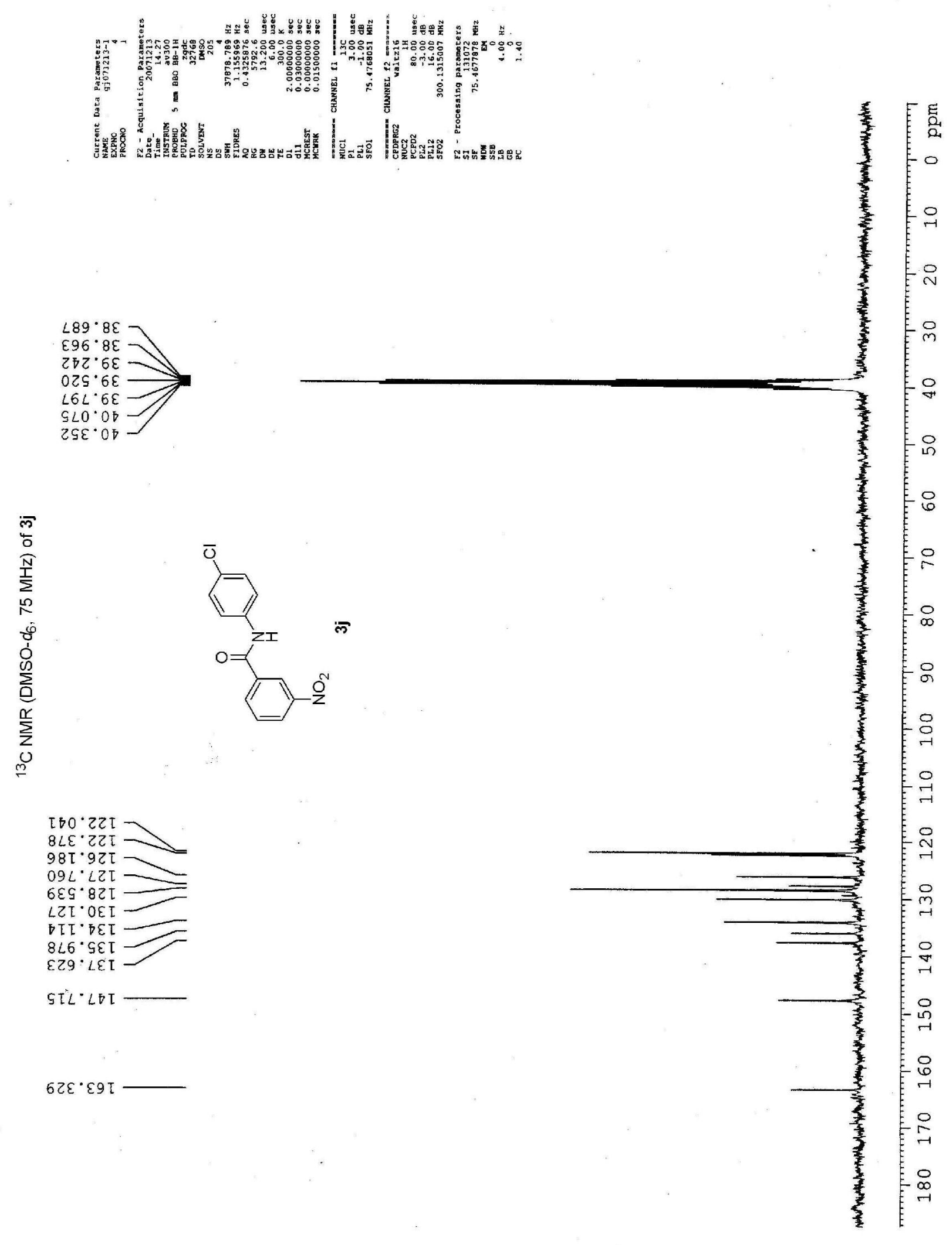




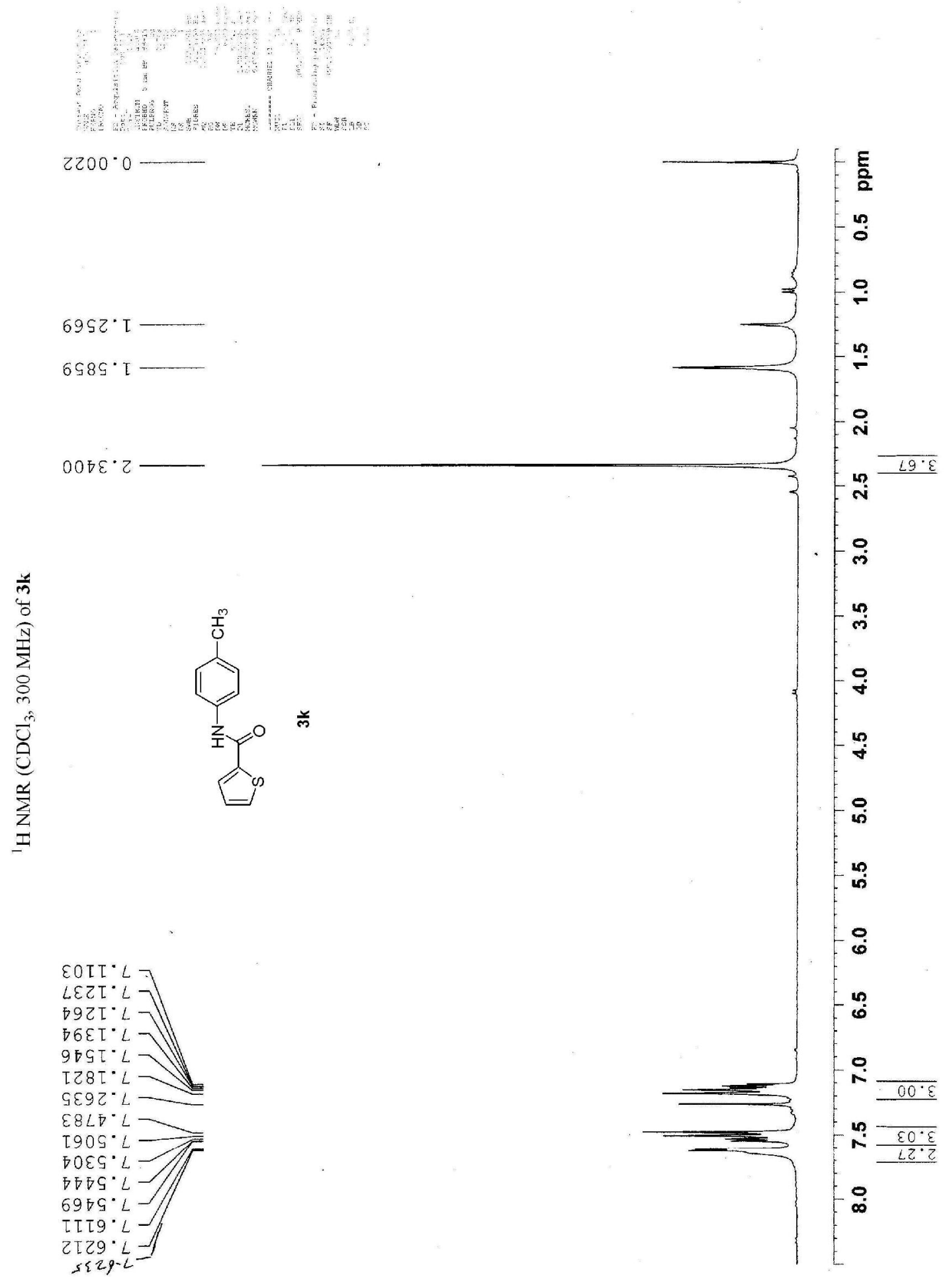

